\title{
FORMAÇÃO DE PROFESSORAS NORMALISTAS RURAIS NOS LONGÍNQUOS RINCÕES DO TERRITÓRIO FEDERAL DO GUAPORÉ, AO NORTE DO BRASIL, EM PORTO VELHO/RO (1947 -1951)
}

\author{
FORMACIÓN DE PROFESORES NORMALISTAS RURALES EN LOS LARGOS \\ RINCONES DEL TERRITORIO FEDERAL DE GUAPORÉ, BRASIL DEL NORTE, EN \\ PORTO VELHO / RO (1947-1951)
}

\begin{abstract}
FORMATION OF RURAL NORMALIST PROFESSORS IN THE FARFLUNG CORNERS OF THE FEDERAL TERRITORY OF GUAPORÉ, IN THE NORTH OF BRAZIL, IN PORTO VELHO/RO (1947 - 1951
\end{abstract}

\author{
Cleicinéia Oliveira de SOUZA ${ }^{1}$ \\ Nilce Vieira Campos FERREIRA ${ }^{2}$
}

RESUMO: Neste artigo analisamos a formação de professoras rurais no Curso Normal Regional Carmela Dutra - CNRCD, entre os anos de 1947 a 1951, a partir de documentos oficiais, tais como Regimento Interno do CNRCD, requerimentos, relatórios e imprensa oficial. Focamos nossa discussão em torno do magistério rural ofertado a mulheres na região Norte brasileira, em Porto Velho, município situado no Vale do Guaporé, atualmente capital de Rondônia. O texto está dividido em duas partes: primeiro, voltamos nosso olhar para as particularidades dessa formação para atuação no magistério rural, a partir do cruzamento entre referenciais teóricos estudados e informações sistematizadas da investigação realizada. $\mathrm{Na}$ segunda parte, abordamos aspectos da formação oferecida no CNRCD, em Porto Velho/RO, Território Federal do Guaporé.

PALAVRAS-CHAVE: História da educação feminina. Formação de professoras rurais. Curso normal regional Carmela Dutra.

RESUMEN: En este artículo analizamos la formación de profesoras rurales en el Curso Normal Regional Carmela Dutra - CNRCD, entre los años de 1947 a 1951, a partir de documentos oficiales como el Reglamento interno de CNRCD, requisitos, informes y prensa oficial. Centramos nuestra discusión en torno del magisterio rural ofertado a las mujeres en la región del norte de Brasil, en Porto Velho, municipio ubicado en el valle de Guaporé, actualmente capital de Rondônia. El texto está dividido en dos partes: primero, dirigimos

\footnotetext{
${ }^{1}$ Universidade Federal de Mato Grosso, Cuiabá - Mato Grosso - Brasil. Doutoranda do Programa de PósGraduação em Educação (UFMT/IE). Bolsista da Coordenação de Aperfeiçoamento de Pessoal de Nível Superior (CAPES). Pesquisadora do Grupo de Pesquisa e Estudos em História da Educação, Instituições e Gênero (GPHEG). ORCID: http://orcid.org/0000-0003-3052-7754. E-mail: cleicineiao.souza@gmail.com

${ }^{2}$ Universidade Federal de Mato Grosso, Cuiabá - Mato Grosso - Brasil. Doutora em Educação pela Universidade de Uberlândia (UFU). Professora Adjunta da Universidade Federal de Mato Grosso (UFMT)/Instituto de Educação (IE)/DTFE/Cuiabá/MT e do Programa de Pós-graduação em Educação (PPGE)/Cuiabá/MT. Coordenadora da Rede de Pesquisa, Ensino e Extensão em Educação das Regiões CentroOeste e Norte do Brasil e América Latina (RECONAL-Edu); do Centro Memória Viva do Instituto de Educação da UFMT/Cuiabá (CMVIE); Grupo de Pesquisa e Estudos em História da Educação, Instituições e Gênero (GPHEG). ORCID: http://orcid.org/0000-0002-9165-0011.E-mail: nilcevieiraufmt@gmail.com
}

RIAEE - Revista Ibero-Americana de Estudos em Educação, Araraquara, v. 15, n. 2, p. 492-507, abr./jun. 2020. e-ISSN: 1982-5587. 
nuestra mirada a las particularidades de esta formación para actuar em el magisterio rural, a partir de la relacion entre las referencias teóricas estudiadas y la información sistematizada de la investigación realizada. En la segunda parte, abordamos aspectos de la formacion ofrecida en CNRCD, en Porto Velho / RO, Territorio Federal de Guaporé.

PALABRAS CLAVE: Historia de educación femenina. Formación de profesoras rurales. Curso normal regional Carmela Dutra.

ABSTRACT: In this article we analyzed the formation of rural teachers in the Carmela Dutra Regional Normal Course - CNRCD, between 1947 and 1951, from official documents such as CNRCD Internal Regulations, applications, reports and official press. We focus our discussion around the rural magisterium offered to women in the Brazilian North region, in Porto Velho, a municipality located in the Guaporé Valley, currently the capital of Rondônia. The text is divided into two parts: first, we turn our attention to the particularities of this formation to a ct in the rural magisterium, from the intersection between studied theoretical references and systematized information of the research. In the second part, we discuss aspects of the training offered at CNRCD, in Porto Velho / RO, Federal Territory of Guaporé.

KEYWORDS: History of female education. Training of rural teachers. Carmela Dutra regional normal course.

\section{Introdução}

No ano de 1947, em Porto Velho/RO, situado na região Norte Brasileira, no chamado Vale do Guaporé, foi ofertado o Curso Normal Regional Carmela Dutra - CNRCD ${ }^{3}$. Nossa análise tem início a partir do processo de implantação e criação do Curso Normal Regional Carmela Dutra e se encerra no ano de 1951, quando o diretor do INEP no período, Murilo Braga, concedeu autorização preliminar para o funcionamento do CNRCD.

Analisamos fontes coletadas no Arquivo Histórico do Instituto Nacional de Estudos e Pesquisas Educacionais Anísio Teixeira (INEP), em Brasília, e alguns documentos ${ }^{4}$ constantes na imprensa oficial.

Embora nos apoiemos em fontes escritas, entendemos que, como exposto por Paul Ricoeur (2007), seja necessário desmistificar a veracidade de fontes documentais, o que nos permite, portanto, analisar, indagar o documento que descobrimos nos arquivos, para então conjecturarmos possibilidades que, por vezes, não estão explícitas nas fontes que foram

\footnotetext{
${ }^{3}$ Essa investigação conta com apoio do Conselho Nacional de Desenvolvimento Científico e Tecnológico CNPq e se inscreve no âmbito do projeto "Formação de Professoras Missioneiras nas Regiões Centro-Oeste e Norte: Mato Grosso e Rondônia/Brasil (1936-1963)", coordenado por Nilce Vieira Campos Ferreira, proposto para o triênio 2018-2021.

${ }^{4}$ Disponível em: http://bndigital.bn.gov.br/hemeroteca-digital/. Acesso em: jan 2020.
} 
coletadas, afinal o "[...] documento não é simplesmente dado, como a ideia de rastro deixado poderia sugerir. Ele é procurado e encontrado. Bem mais que isso, ele é circunscrito, e nesse sentido constituído, instituído documento, pelo questionamento". (RICOEUR, 2007, p. 189).

Considerando que o documento pode ser então constituído por determinados pressupostos de quem o elaborou ou mesmo o conservou, há que se ter cautela ao indagá-lo. Os questionamentos ao documento possibilitam que adotemos um caminho a ser seguido. Trata-se, portanto, de debatermos as fontes de informação das quais dispomos à luz de uma dialética que nos permite refletir e analisar metodologicamente o que encontramos no registro documental, pois o "alargamento temático e as novas produções intelectuais resultantes merecem, hoje, uma avaliação crítica". (RAGO, 1995, p. 81).

Os questionamentos levantados ao longo da análise documental devem direcionar a pesquisa para o mais próximo possível da "verdade", uma vez que é preferível questionar o documento mesmo quando não há clareza do que se pretende descobrir. Para nós, desde o início e sempre, o documento como fonte de pesquisa deve ser passível de perguntas, ancoradas em múltiplas possibilidades, mas nossos questionamentos devem ser abertos de forma que “[...] possa desde o início servir de ímã às limalhas do documento. O explorador sabe muito bem, previamente, que o itinerário que ele estabelece, no começo, não será seguido ponto a ponto. Não ter um, no entanto, implicaria o risco de errar eternamente ao acaso". (BLOCH, 2002, p. 79).

Ao estabelecer um percurso, mesmo sabendo que não será seguido em sua totalidade, como dito por Bloch (2002), permite que sigamos um determinado roteiro, mas não estabelece certezas, pois é possível que as respostas aos nossos questionamentos nos tragam surpresas, pontos de vista para os quais ainda não havíamos atentado. Quando questionamos as fontes, evitamos determinados equívocos que podem se perpetuar por conta do acaso, o que nos leva a confirmar a importância de refletimos a respeito dos escritos que temos em mãos, afinal a "[...] reflexão se faz tanto mais necessária, quanto mais nos damos conta de que a História não narra o passado, mas constrói um discurso sobre este”. (RAGO, 1995, p. 81).

Apoiadas nessa linha de raciocínio, defendemos que para historicizar a escolarização das mulheres no magistério rondoniense olhamos para as fontes descobertas buscando um novo olhar para investigar a formação ofertada para normalistas rurais nos rincões mais remotos brasileiros, ao norte do país, um local ainda pouco pesquisado, de tal forma que pudéssemos registrar um pouco dessa história que ainda está silenciada ou como meio de “[...] recuperar a trajetória das mulheres no magistério [...] em tirar da obscuridade as 
professoras que se encarregam no país, há mais de um século, da educação fundamental”. (ALMEIDA, 1998, p. 26).

Essa discussão surge a partir de pesquisas que desenvolvemos buscando a inclusão das mulheres na historiografia da educação, em específico na região mais ao Norte do Brasil ${ }^{5}$, buscando "[...] não apenas momentos inesperados da presença feminina em acontecimentos históricos, mas também um alargamento do próprio discurso historiográfico", o que nos permite pensar além do "sujeito universal" (RAGO, 1995, p. 81) na investigação de práticas e ações marcadamente voltadas para a escolarização e formação de mulheres.

\section{Curso normal regional e rural no Brasil}

A partir do ano de 1947, no Brasil, houve uma preocupação com as políticas públicas educacionais direcionadas a investimento nos cursos normais regionais e rurais. $\mathrm{O}$ governo brasileiro daquela época destinou recursos financeiros para estados e territórios do Brasil com a finalidade de criar e desenvolver cursos normais regionais e rurais destinados à formação e aperfeiçoamento de professoras rurais. De forma explícita, Lourenço Filho descreveu que “[...] o desenvolvimento, do ensino normal regional e rural, realizado a partir de 1947, tem consistido em auxílios distribuídos a 16 Estados e quatro Territórios, para a construção de 51 edifícios e ampliação ou reforma de outros 19”. (LOURENÇO FILHO, 2001, p. 81).

O governo brasileiro distribuiu recursos financeiros para pelo menos duas formações distintas relacionadas ao magistério rural. Uma delas voltava-se para a formação em cursos normais regionais e rurais com o objetivo de habilitar professores para lecionar nas áreas rurais. Outra formação previa cursos de treinamento ou aperfeiçoamento de professores que já trabalhavam na área rural. Para que esses cursos fossem ofertados, convênios foram firmados pela União com estados, municípios e outras instituições religiosas, com as quais foram estabelecidos “[...] uma série de Acordos e Projetos de trabalho com os governos estaduais e municipais e, ainda, com diferentes instituições, estabelecendo cooperação recíproca e comprometendo-se a uma contribuição financeira”. (CONCEIÇÃO, 1954, p. 14).

Na maioria das vezes, cabia ao Ministério da Agricultura implementar esses cursos nas áreas rurais e, a partir de sua oferta efetiva, o governo brasileiro intentava “[...] influenciar o desenvolvimento de condições políticas e sociais que permitissem às famílias manter-se em suas localidades". Com isso, cursos de treinamento ou de extensão rural procuravam formar

${ }^{5}$ O Grupo de Pesquisa e Estudos em História da Educação, Instituições e Gênero (GPHEG) tem se voltado para as pesquisas sobre história da educação das mulheres. Disponível em: https://www1.ufmt.br/ufmt/un/cmvmt. Acesso em: jan 2020. 
professoras de modo aligeirados com o intuito de divulgar "[...] técnicas para a melhoria das condições de vida das famílias localizadas no meio rural”. (FERREIRA, 2014, p. 33).

Seguindo normas da sociedade urbana brasileira que se queria moderna, os governantes brasileiros trataram de difundir determinadas formas de pensar, em específico nos processos de escolarização destinados às mulheres. Podemos problematizar que "[...] os colégios femininos contribuíram de forma expressiva para o abandono da antiga mentalidade rural”. (FERREIRA; SOUZA; PRADO, 2019, p. 92).

A formação feminina para atuação no magistério tinha como finalidade precípua levar as professoras ali formadas a uma participação ativa nas comunidades nas quais porventura se instalassem, de modo a transformar as condições daquelas localidades. Para isso, as práticas pedagógicas incentivavam a criação de clubes de mães, clubes de líderes rurais, bem como a participação em quaisquer atividades da comunidade nas quais as professoras estavam inseridas.

Escolas regionais ou normais rurais para a formação de professoras para atuar nas áreas rurais já eram discutidas no Brasil desde os anos de 1930, por educadores e intelectuais da educação brasileira. Em 1942, o Oitavo Congresso Nacional de Educação, realizado em Goiânia, no qual os mato-grossenses Gervásio Leite e Francisco Antônio Ferreira Mendes discorreram sobre o ensino rural no estado de Mato Grosso, esteve sob a relatoria de Sud Mennucci, defensor das escolas normais regionais e normais rurais. Naquele Congresso grande parte dos textos apresentados tratou das escolas rurais e formação de professoras e professores rurais.

Gervásio Leite (1944, p. 139), advogado e professor em Mato Grosso, afirmou que o ensino rural e a formação de professoras ocorriam de forma precária no estado. Para ele, “[...] os professores rurais não têm nenhum preparo especial. Não são habilitados por uma escola especializada no conhecimento daquelas indispensáveis noções necessárias para se tornarem de fato, professores especializados".

Com uma visão equivocada, a nosso ver, uma vez que o estado não propiciava condições efetivas e adequadas de formação às professoras mato-grossenses, Leite (1944, p. 139), ao afirmar que elas não poderiam ensinar além do "ler, escrever e contar", excluía a principal característica da professora rural, que a despeito de todas as dificuldades que vivia tratava de "[...] conhecer e tentar encaminhar resoluções para os problemas do meio a que servem", como dito por ele mesmo.

O relator do Oitavo Congresso Nacional de Educação, após ouvir diversos profissionais da área de ensino, afirmou que "um novo tipo de professor" deveria ser formado 
em escolas normais rurais. Essas escolas se voltariam para a preparação de docentes com "amplos e seguros conhecimentos de agricultura, de indústrias rurais, de economia rural". (MENNUCCI, 1944, p. 291).

Acreditamos que muitas discussões promovidas no âmbito do Congresso realizado em Goiânia influenciaram na promulgação, poucos anos, depois do Decreto-Lei n. 8.530, em 2 de janeiro de 1946, que instituiu a Lei Orgânica do Ensino Normal com a finalidade de: I) prover à formação do pessoal docente necessário às escolas primárias; II) habilitar administradores escolares destinados às mesmas escolas; III) desenvolver e propagar os conhecimentos e técnicas relativas à educação da infância. (BRASIL, 1946).

A partir do Decreto-Lei 8.530, ficou estabelecido que o curso de regentes de ensino primário seria ofertado em quatro séries anuais, vinculado ao curso primário. O mesmo Decreto estabeleceu que o Curso Normal Regional deveria funcionar nas áreas de colonização, ou seja incluindo a região Norte, e os últimos anos de estudo deveriam ser direcionados para ensinamentos que abrangessem a cultura e costumes da população da região.

O curso de formação de professores primários, descrito no Decreto-Lei 8.530, deveria ser ofertado em três séries anuais, articulado ao curso ginasial, mas também poderia ser ofertado em dois anos, de forma intensiva.

A partir da promulgação da Lei Orgânica do Ensino Normal, na região Norte do Estado brasileiro, a concepção de formação de professoras rurais atendia a alguns princípios essenciais, a nosso ver, acolhendo as diretrizes básicas e atividades pedagógicas que aproximassem as mulheres da vida campesina, de tal forma que elas pudessem compreender minimamente princípios de "agricultura", que fossem ao mesmo tempo enfermeiras, cuidadoras das famílias, das crianças, enfim, que direcionassem "[...] para o campo com a convicção inabalável de que era preciso ser ali um incentivador de progresso". (MENNUCCI, 2006, p. 83).

O meio rural, desse modo, estaria propício às mudanças que gerariam progresso das localidades, segundo os interesses governamentais. Conforme esse critério, a criação de escolas normais regionais e rurais se deu em localidades nas quais havia demanda suficiente de pessoas para se matricularem nos cursos de formação para docentes rurais e, em cujo entorno houvesse significativo número de escolas rurais funcionando com a atuação de professoras e professores sem formação específica.

\section{O curso normal regional Carmela Dutra no Território Federal do Guaporé}


No ano de 1947, o Curso Normal Regional Carmela Dutra foi criado em Porto Velho. A instituição escolar que ofertou o curso recebeu o nome da primeira dama brasileira Carmela Teles Leite Dutra, esposa de Eurico Gaspar Dutra ${ }^{6}$.

Criado por meio do Decreto $\mathrm{n}^{\circ} 47$, de 19 de dezembro de 1947, emitido pelo Governador do Território Federal do Guaporé, Frederico Trotta, o regimento interno da instituição escolar foi aprovado pelo Decreto $n^{\circ} 78$ de 28 de abril de 1948, emitido também por Trota, mas o curso começou a funcionar efetivamente em 17 de abril de 1948, a partir de a construção da "[...] sede do estabelecimento, cidade de Porto Velho, capital do Território Federal do Guaporé”. (TROTTA, 1947, p. 1).

A justificativa para a criação do CNRCD foi descrita por Eva Garfinkel, em um relatório encaminhado ao Ministério da Justiça e Negócios Interiores, no ano de 1946, no qual a técnica em educação do INEP descreveu os motivos para a instalação e funcionamento do CNRCD em Porto Velho/RO.

Quanto ao ensino normal, esteve ele paralisado no Território durante o ano de 1947, visto ter a Escola Normal Rural Maria Auxiliadora mantido em 1946, apenas a matrícula na $3^{\mathrm{a}}$ série -7 alunas (dados do I.B.G.E), sendo em seguida transformada em secção feminina do Ginásio D. Bosco, de acordo com as afirmações do relatório. A 19 de novembro de 1947, porém, o governo territorial decretou a criação do Curso Normal Regional "Carmela Dutra", que entrará em funcionamento em março do ano Corrente. (GARFINKEL, 1948, p. 3).

Como citado no excerto, acima o ensino normal não havia sido ofertado em 1947 e em 1946 apenas uma escola confessional havia ofertado a formação para apenas 7 alunas, no Território Federal do Guaporé. A Escola Normal Rural Maria Auxiliadora ${ }^{7}$, era uma escola religiosa salesiana, portanto, confessional, que ministrava, além do curso normal rural, outros cursos específicos para mulheres, como corte e costura, bordados, artes culinárias, enfim, os denominados trabalhos manuais femininos. (PRADO, 2017).

Com isso, possivelmente a criação de CNRCD tenha se dado no intuito de atender ao Decreto-Lei n. 8.530, no que dizia respeito à formação de professoras para lecionar na área rural, bem como, provavelmente para obter recursos de programas do governo que se voltassem para essas modalidades de ensino.

\footnotetext{
${ }^{6}$ Eurico Gaspar Dutra foi Presidente do Brasil no período de 1946 a 1951 e Carmela Dutra era sua esposa. Embora nunca tenha atuado como professora ou mesmo na área de educação na cidade de Porto Velho, acreditamos que como se dá comumente no Brasil, o nome da instituição escolar tenha sido atribuído por algum interesse político na região.

${ }^{7}$ Interessante estudo a respeito foi desenvolvido por Fernanda Batista do Prado no ano de 2017. Disponível em: http://www1.ufmt.br/ufmt/un/secao/13112/cmvmt. Acesso em: jan 2020.
} 
Um campo de questionamento centrou-se nessa constatação da necessidade de obtenção de recursos para a formação de professores. Parece-nos que o governador do Território Federal do Guaporé, Frederico Trotta, durante o seu exercício, manteve uma atitude vigilante em busca da captação de recursos financeiros. Encontramos um documento contento uma descrição minuciosa de solicitação dos meios monetários a serem destinados ao custeio do Curso Normal Regional na Escola Carmela Dutra. A correspondência foi endereçada à Clemente Martins, diretor do INEP.

Nessa solicitação, Frederico Trotta teceu elogios à campanha que o Ministério da Educação e Saúde estava desenvolvendo e, ao final da mensagem, pediu os meios financeiros indispensáveis à construção de um dormitório ${ }^{8}$ para as alunas que vinham de outras localidades do Território Federal do Guaporé para estudar na capital, Porto Velho.

Trotta descreveu a repercussão nacional da Campanha Nacional de Educação de Adolescentes e Adultos (CEAA $)^{9}$, bem como os resultados que conseguia visualizar no caso de disponibilização desses recursos. Trota também elogiou a campanha empreendida, destacando que era um movimento que promovia a "[...] recuperação do homem amparando-o pela educação, civilizando-o através das escolas primárias". Trotta destacou ainda que o país estava “[...] sendo coberto de escolas primárias em dois anos mais do que em cinquenta anos de República”. (TROTTA, 1947, p. 1-2).

Por trás dessa aparente convergência e apreciação de Trotta, entretanto, transpareceu uma crítica ao "mestre-escola"10", a mencionar que a “[...] nomeação de elementos improvisados e portanto ineficientes" o levou a emitir o Decreto $\mathrm{n}^{\circ} 47$, de 19 de dezembro de 1947, estipulando “[...] a criação do Curso Normal Regional que recebeu o nome de Carmela Dutra em homenagem a extinta que tantos serviços prestou ao país no setor educacional" ${ }^{\text {. }}$.

Configurado o cenário, Trotta (1947) ofereceu como contrapartida para os recursos a serem disponibilizados ao CNRCD os serviços e mão de obra para a construção do prédio a ser destinado como local de funcionamento do curso, com o "[...] objetivo: dotar Guaporé de professôres primários habilitados”.

\footnotetext{
${ }^{8}$ Nesse período era comum que as escolas funcionassem em sistema de internato e oferecessem alojamento para estudantes. No sistema de internato, as alunas permaneciam na instituição escolar em tempo integral. Contudo, era um sistema oneroso para a maioria das instituições e quase sempre funcionavam por pouco tempo, logo sendo extintos, como descrito por Ferreira (2014).

${ }^{9}$ Entre os anos de 1945 e 1946, o INEP solicitou aos estados que incentivasse a ampliação do ensino supletivo, para isso criou a Campanha Nacional de Educação de Adolescente e Jovens (CEAA), com objetivo de destinar recursos aos estados para a ampliação da Campanha. Paiva (1983, p. 160).

${ }^{10} \mathrm{O}$ Mestre-Escola foi um professor que lecionava para um grupo de alunos com conteúdo e idades distintas antes da constituição da escola normal no Brasil, nos anos 1830; nesse período as normas eram bem rígidas, o erro do aluno tinha como punição a palmatória entre outros castigos, conforme Villela (2007).

${ }^{11}$ O CNRCD recebeu esse nome quando Carmela Dutra já era falecida.
} 
Essa clara alusão do governador permite-nos a percepção de uma verdadeira cruzada para formar professoras preparadas para educar a população que vivia no meio rural, e de que na localidade prevalecia a oferta de ensino rural que era ministrado por docentes leigas e leigos, isto é, professoras e professores que não possuíam habilitação específica para a atuação no magistério. A respeito de essa denominação, Carlos Rodrigues Brandão (1986, p. 13) mencionou que "[...] o professor leigo de carreira, em geral a pessoa que, sem nunca haver chegado à posição de um professor formado, dedicou quase toda a sua vida ao magistério, principalmente em áreas rurais", uma realidade comum também às terras rondonienses naquele período.

O CNRCD, como escola de formação no meio rural, estava consorciado com os ideais de Trotta (1947), que fez mais algumas exigências e requereu "[..] o auxílio de seiscentos mil cruzeiros $(\mathrm{Cr} \$ 600$ 000,00) destinados à construção e equipamento de um moderno pavilhão dormitório, sob modelo e planta, fornecidos pelo eficiente e esclarecido INEP”. Esses recursos deveriam ser disponibilizados com "[...] a máxima urgência" para que ele conseguisse construir o prédio no qual o CNRCD funcionaria adequadamente. Trota ainda enfatizou “[...] se essa quantia fosse colocada desde já a nossa disposição, talvez até maio já estivesse o pavilhão em uso, pois a divisão de Obras do Território sacrificaria todos os demais serviços para dar prioridade a esse". (TROTTA, 1947, p. 2).

Mesmo apresentada não somente como fator de melhoria para a formação de professoras rurais, mas também como uma iniciativa do governo, o que aparentemente seria um compromisso com o desenvolvimento da educação rural no estado, algumas considerações podem ser levantadas a partir da solicitação efetivada por Trotta. Uma delas refere-se possivelmente ao descontentamento que a população vinha demonstrando com as condições das escolas existentes na região. Outra, refere-se à larga campanha empreendida por Getúlio Vargas na época para ocupação das regiões mais ao norte do país.

Getúlio Vargas, em 9 de outubro de 1940, havia visitado a região Norte quando discursou que o Brasil e o mundo direcionavam seu olhar para o desenvolvimento da região Norte, pois era uma área extensa e rarefeita, cuja concentração e exploração de riquezas deveria ser priorizado. Vargas então estabeleceu o "reerguimento da Amazônia" com o objetivo de explícito de aumentar as áreas comerciais e industriais na região.

Vim para ver e observar de perto as condições de realização do plano de reerguimento da Amazônia. Todo o Brasil tem os olhos voltados para o Norte, com o desejo patriótico de auxiliar o surto do seu desenvolvimento. E, não somente os brasileiros, também estrangeiros, técnicos e homens de negócio, virão colaborar nessa obra, aplicando-lhe a sua experiência e os

RIAEE - Revista Ibero-Americana de Estudos em Educação, Araraquara, v. 15, n. 2, p. 492-507, abr./jun. 2020. e-ISSN: 1982-5587. 
seus capitais, com objetivo de aumentar o comércio e as indústrias, e não, como acontecia antes, visando formar latifúndios e absorver a posse da terra, que, legitimamente, pertence ao caboclo brasileiro. (VARGAS, 1940, p. 79).

O discurso de Vargas ressaltou que a região Norte era um local visado pelos interesses nacionais e internacionais, ocupado por extensos latifúndios, era sua intenção, entretanto, que a posse da terra pertencesse aos caboclos que ali residiam, marca do populismo que defendia. Entretanto, ao mencionar que homens de negócio ali aplicariam seus capitais, deixou transparecer que o capitalismo avançava para aquela região. Certamente, para ocupar esses espaços, foram necessários investimentos em escolas e a formação de professoras para educar jovens e crianças.

Coadunando com nossas reflexões, no ano de 1948, Murilo Braga, diretor do INEP, respondeu à correspondência de Frederico Trotta e solicitou outras informações para que pudesse destinar recursos para a "[...] construção e equipamento de um pavilhão-dormitório para alunas do Curso Normal Regional desse Território”. Braga, ressaltou que assim procedendo estaria “o INEP habilitado para um estudo e solução conveniente do assunto: a) levantamento do terreno disponível; b) fotografias do local; c) - elementos discriminativos do orçamento das obras". (BRAGA, 1948, p. 1).

Em 11 de março de 1949, a diretora de Divisão de Educação, Laudimia Trotta, encaminhou um relatório ao diretor do INEP intitulado "Descrição do prédio onde funciona provisoriamente o CNR e suas instalações didáticas" contendo os dados solicitados por Braga. O relatório continha um quadro sinóptico descritivo da “[...] construção, situação do prédio, instalações higiênicas, abastecimento d'água, dimensões, iluminação, mobiliário e material didático das salas de aula, instalações para educação física e gabinete médico-biométrico". (TROTTA, 1949. p. 1-2).

Em 23 de janeiro de 1951, o Diretor do INEP Murilo Braga, após análise dos documentos enviados, concedeu "a título precário, ao Curso Normal Regional 'Carmela Dutra' a autorização preliminar, a ser confirmada tão logo seja construído o prédio próprio" (BRAGA, 1951, p. 2).

Contatamos que a partir dessa autorização teve início a construção do prédio próprio para o CNRCD, que funcionaria ao lado do Grupo escolar Duque de Caxias, cumprindo assim as exigências do Decreto-Lei 8.530 da Orgânica do Ensino Normal de 1946, que normatizou que para o funcionamento do curso normal era obrigatório ter anexo escolas primárias para a prática do ensino. 
Vale destacar, contudo, que o CNRCD, desde seu início, para o desenvolvimento de suas atividades, houve, por parte poder público, responsável pela instituição escolar, a previsão e disponibilização tanto de recursos financeiros quanto pedagógicos. No cotidiano da instituição escolar havia recursos didáticos disponíveis para a realização de aulas práticas, a exemplo, um local de experimentação para as práticas agrícolas.

\section{CNRCD: "Embrião do Florescente Curso de Magistério"}

O CNRCD, a princípio, foi ofertado no Grupo Escolar Duque de Caxias ${ }^{12}$ em Porto Velho, em duas salas daquela instituição escolar, até a construção da Escola Normal do Guaporé, que mais tarde, em 1956, foi denominada Escola Normal Carmela Dutra.

Esse embrião do florescente curso de Magistério funcionou numa parte do então Grupo Escolar "Duque de Caxias", nas duas salas dos fundos, Só pelos idos de 1954 ou 55, passou a Escola Normal do Guaporé (já no imponente prédio da avenida Farqhuar) depois mudou para a denominação de Escola Normal "Carmela Dutra", depois foi Colégio Normal "Carmela Dutra" e finalmente Escola Estadual de $1^{\circ}$ e $2^{\circ}$ Graus "Carmela Dutra". (MENEZES, 1982, p. 1).

Como podemos notar no excerto acima, a construção de um local adequado para o funcionamento CNRCD era imprescindível, pois possibilitaria que as aulas fossem ministradas no sistema de internato para estudantes provenientes de localidades do interior do Território Federal do Guaporé.

Outro fato que possivelmente determinou a criação da instituição escolar foi o fato de que o grupo escolar era destinado ao atendimento de crianças nas séries primárias, enquanto o curso normal atenderia ao ensino secundário e respectivas formações, a exemplo, a oferta de cursos normais regionais e cursos de treinamento ou aperfeiçoamento para professoras rurais.

As normas para o funcionamento da instituição escolar contavam no Regimento Escolar, que dispunha que o curso fosse ofertado “[...] em sede própria na cidade de Porto Velho, capital do Território, sob o regime de internato feminino, a fim de receber alunas de todos os pontos do Território, e externato misto". (CNRCD, 1948 p. 4).

${ }^{12}$ Grupo Escolar Duque de Caxias, criado pelo Decreto no 42 de 6 de setembro de 1947 em Porto Velho. A princípio o prédio do Grupo Escolar era uma residência cedida pela Estrada de Ferro Madeira Mamoré na avenida Farhuar, ao lado do futuro prédio no qual funcionaria o Curso Normal Regional Carmela Dutra. Disponívem em:

http://www.rondonia.ro.gov.br/historia-de-rondonia-frederico-trotta-o-3o-governador-ficou-menos-de-um-anono-cargo-e-apoiou-a-educacao/. Acesso em: jan 2020. 
A adequação das escolas às necessidades locais era um objetivo enunciado desde a sua criação pelos governantes brasileiros, mas nem sempre alcançado. No caso em estudo, o local, um alojamento para que as cursistas permanecessem na localidade durante as aulas que ocorriam em período integral, foi completado; sem ele, talvez o CNRCD não tivesse funcionado.

Isto por que, no ano de 1948, no atual estado de Rondônia, o então Território Federal do Guaporé era uma enorme extensão rural, com $237.590,547 \mathrm{~km}$ de área rarefeita. Os municípios que contavam com escolas que ofertavam o curso normal eram apenas as localidades de Porto Velho e Guajará-Mirim, uma pequena cidade localizada às margens do Rio Guaporé e distante de Porto Velho cerca de 330,9 km. Nas demais localidades existiam apenas pequenos povoados, o que justifica a preocupação de Trotta (1949) com a criação de um alojamento para facilitar que as mulheres pudessem frequentar o curso de formação de professoras rurais.

$\mathrm{Na}$ verdade, nas mais diversas regiões, as escolas normais brasileiras, fossem urbanas ou rurais, geralmente funcionaram "[...] em regime de internato, onde as moças aprimoravam os hábitos que fariam parte do dote matrimonial"; com essas condições de estrutura da instituição era possível conciliar a escolarização das moças com a preparação de "futuras esposas". (NOSELLA; BUFFA, 1996, p. 31).

As normas para o funcionamento do internato, classificado de cunho assistencial para estudantes que se matriculassem como internas na instituição e que não teriam condições de retornar ao ambiente familiar cotidianamente devido às distâncias e às dificuldades de transporte $^{13}$, foram descritas no Regimento Interno do CNRCD. O mesmo Regimento garantia ainda que, além da educação gratuita, o Território se responsabilizaria pela alimentação, tratamento médico e dentário das cursistas.

Art. $33 .^{\circ}$ - O internato tem caráter de assistência social, sem prejuízo de seu programa educativo, em vista da finalidade do estabelecimento.

Art. 34. ${ }^{\circ}$ - Às alunas internadas fornecerá o Território, alimentação, tratamento médico e dentário e ministrará educação de acordo com a organização e finalidade do estabelecimento. (CNRCD, 1948, p. 11).

A par dessas considerações, lembramos ainda que à formação para a atuação no meio rural cabia uma clara distinção: formar pessoas para modificar o cotidiano das comunidades rurais. Isto é, às professoras formadas por essas escolas era atribuída uma missão: modificar

\footnotetext{
${ }^{13}$ No período em estudo, os meios mais comuns para o transporte de pessoas no Território Federal de Rondônia eram fluviais ou por aviação, o que tornava difícil e demorada a locomoção pelo Território do Guaporé.
} 
culturas campesinas nas regiões rurais, tanto brasileiras quanto rondonienses, desse modo, permanecendo nos alojamentos, parece-nos que seria mais fácil a aculturação das cursistas a serem formadas.

\section{Considerações}

Políticas públicas para a Educação, no Brasil do Século XX, quase sempre foram promulgadas para modificar hábitos e costumes da maioria da população que vivia nas áreas rurais brasileiras. Diante disso, tanto o Ministério da Educação e Cultura quanto o Ministério da Agricultura estimularam distintas ações educacionais para que homens e mulheres permanecessem no campo.

Na região Norte Brasileira, mais especificamente em Porto Velho/RO, o governador do Território Federal do Guaporé solicitou recursos financeiros para o Ministério da Educação e Cultura visando ofertar um curso de formação para professoras rurais e incluiu o requerimento para a construção de um alojamento para que as cursistas pudessem permanecer no local de estudo.

Por meio da pesquisa realizada é perceptível que algumas atividades e práticas de ensino eram desenvolvidas em espaços escolares com características do meio rural. A exemplo, podemos destacar que no Regimento Interno do CNRCD estava descrito um campo de experimentação para as atividades de práticas agrícolas, para que cursistas vivenciassem o cotidiano da área rural, o que nos permite afirmar que também à instituição coube formar mulheres e homens que atuariam no meio rural com a finalidade de modificar hábitos e costumes.

O que apresentamos até aqui comprova que instituição escolar Carmela Dutra, considerada instituição de formação de professoras rurais, constituiu-se como espaço de exercício de práticas escolares para alteração do meio rural. A escola se tornou uma instituição reconhecida como precursora no Vale do Guaporé, um espaço cujas tentativas de formar professoras rurais marcou-se por valores do período, segundo os quais era preciso modificar o meio rural, e por extensão, o povo que ali habitava.

O período em estudo representa, tanto para a História da Educação brasileira quanto para a História da Educação feminina no Norte do país, um período de consolidação de políticas e práticas de formação de professoras rurais. Era um tempo no qual inúmeras campanhas educativas para homens e mulheres campesinas foram implementadas, o que nos leva a afirmar que cabe investigações mais aprofundadas para melhor interpretar esses 
espaços de formação de modo a compreender as políticas educativas com as quais continuamente nos confrontamos no constante desafio de ensinar e de aprender.

\section{REFERÊNCIAS}

ALMEIDA, Jane Soares de. Mulher e Educação: a paixão pelo possível. São Paulo: UNESP, 1998.

BLOCH, Marc. Apologia da História ou o ofício do historiador. Prefácio Jacques Le Goff. Apresentação à edição brasileira Lilia Moritz Schwarcz. Tradução André Telles. Rio de Janeiro: Jorge Zahar, 2002.

BRAGA, Murilo. Processo n. 2736/49. Autorização para funcionamento de estabelecimento de Ensino Normal em Território. Ministério da Educação e Saúde. Arquivo Histórico do INEP, 1951. p. 2.

BRAGA, Murilo. Processo no 92. Ministério da Educação e Saúde. 15 de março de 1948. Arquivo Histórico do INEP, 1948.

BRANDÃO, Carlos Rodrigues. Os Professores leigos. Em Aberto, Brasília, ano 5, n. 32, out./dez. 1986. Disponível em:

http://rbepold.inep.gov.br/index.php/emaberto/article/viewFile/1612/1584. Acesso em: jan 2020.

BRASIL. Decreto-Lei n. 8.530. Lei Orgânica do Ensino Normal. Rio de Janeiro, 2 de janeiro de 1946, 125 de Independência e 58 da República. Diário Oficial da União, p. 116, 4 jan. 1946. Disponível em: https://www2.camara.leg.br/legin/fed/declei/1940-1949/decreto-lei8530-2-janeiro-1946-458443-publicacaooriginal-1-pe.html. Acesso em: 13 abr. 2019.

CONCEIÇÃO, Diamantina Costa Conceição. Qual o melhor progresso para a dinamização e o desenvolvimento cultural e econômico dos municípios brasileiros. Revista Campanha Nacional de Educação Rural. Ministério da Educação. Arquivo Inep, p. 5-25, 1954.

FERREIRA, Nilce Vieira Campos. Economia Doméstica: ensino profissionalizante feminino no Triângulo Mineiro (Uberaba/MG- 1953-1997). Ed. Paco Editorial: Jundiaí, 2014.

FERREIRA, Nilce Vieira Campos; SOUZA, Cleicinéia Oliveira de; PRADO; Fernanda Batista. História da educação no centro-oeste e norte brasileiros - entre o ofício e a missão: formação de professoras normalistas e missioneiras rurais. Curitiba: Appris, 2019.

GARFINKEL, Eva. Processo no 1625/47. Ministério da Educação e Saúde. 7 de janeiro de 1948.

HISTÓRIA DE RONDÔNIA: Frederico Trotta, o $3^{\circ}$ governador, ficou menos de um ano no cargo e apoiou a educação. Disponível em: http://www.rondonia.ro.gov.br/historia-derondonia-frederico-trotta-o-3o-governador-ficou-menos-de-um-ano-no-cargo-e-apoiou-aeducacao/. Acesso em: 14 abr. 2019. 
LEITE, Gervásio. “Aspecto matogrossense do ensino rural”. In: ABE, Oitavo Congresso Brasileiro de Educação. Goiânia, jun. 1942. Rio de Janeiro, IBGE, 1944. p. 135-42.

LOURENÇO FILHO, Manoel Bergström. A formação de professores: da escola normal à escola de educação. Ruy Lourenço Filho (Org.). Brasília: Instituto Nacional de Estudos e Pesquisas Educacionais, 2001.

MENEZES. Esron Penha de. História Antiga. Alto Madeira, Rondônia, p. 5, 1982. Disponível em:

http://memoria.bn.br/DocReader/DocReader.aspx?bib=843911\&PagFis=8796\&Pesq=curso\% 20normal\%20regional. Acesso em: 14. fev. 2019.

MENNUCCI, Sud. A Crise Brasileira de Educação. 2. ed. São Paulo, SP: Piratininga, 2006.

MENNUCCI, Sud. O Professor Primário da Zonas Rurais: formação, aperfeiçoamento, remuneração e assistência. In: Anais[...] Oitavo Congresso Brasileiro de Educação, 1944. Goiânia, jun. 1942. Serviço Gráfico do IBGE, Rio de Janeiro. 1944. p. 289-300.

NOSELLA, Paolo; BUFFA, Ester. Schola mater. A antiga escola Normal de São Carlos 1911-1933. São Carlos: Ed. Universidade Federal de São Carlos/FAPESP, 1996.

PAIVA, Vanilda Pereira. Educação popular e educação de adultos. São Paulo: Edições Loyola, 1983.

PRADO, Fernanda Batista do. Entre o Oratório e a Profissão: formação de professoras na Escola Normal Rural Nossa Senhora Auxiliadora em Porto Velho/RO (1930-1946).

Orientadora: Nilce Vieira Campos Ferreira. 2017. 157f. Dissertação (Mestrado em Educação). Universidade Federal de Mato Grosso, Cuiabá, 2017. Disponível em:

http://ri.ufmt.br/handle/1/1998. Acesso em: jan. 2020.

RAGO, Maragreth. As mulheres na historiografia brasileira. In: LOPES, Zélia Silva. Cultura Histórica em debate. Cultura Histórica em Debate. São Paulo: UNESP, 1995. p. 81-91.

RICOEUR, Paul. A memória, a história, o esquecimento. Tradução: Alain François et. al. Campinas, SP: Editora da Unicamp, 2007.

TERRITÓRIO FEDERAL DO GUAPORÉ. Regimento Interno do Curso Normal Regional Carmela Dutra. Divisão de Educação. Arquivo Histórico do INEP, 1948.

TROTTA, Frederico. Auxílio para o Curso Normal Regional. Território Federal do Guaporé. Arquivo Histórico do INEP, n. 12-39, pasta 4, 1947.

TROTTA, Laudimia. C.N.R Carmela Dutra: descrição do prédio onde funciona provisoriamente o C.N.R e de suas instalações didáticas. Divisão de Educação do Território Federal do Guaporé. 1949. p. 1-2.

TROTTA, Laudimia. O Guaporé. Território Federal do Guaporé, Arquivo Histórico do INEP, ano I, n. 29, p. 1, 24 fev. 1948. 
TROTTA, Laudimia. Ofício no 128/DE. Diretoria da Divisão de Educação do Território Federal do Guaporé. Arquivo Histórico do INEP.

VARGAS, Getúlio. O destino brasileiro do Amazonas. Discurso pronunciado no "Ideal Club" de Manaus, agradecendo o banquete oferecido pelo interventor e pelas classes conservadoras do Estado. Manaus, AM, 9 out. 1940. Disponível em:

http://www.biblioteca.presidencia.gov.br/presidencia/expresidentes/getuliovargas/discursos/1 940/31.pdf. Acesso em: 28 abr. 2019.

VILLELA, Heloisa de Oliveira Santos. O mestre-Escola e a Professora. In: LOPES, Eliane Marta Teixeira; FARIA FILHO, Luciano Mendes; VEIGA, Cynthia Greive (org.). 500 anos de Educação no Brasil. Belo Horizonte: Autêntica, 2007. p. 95-133.

\section{Como referenciar este artigo}

SOUZA, Cleicinéia Oliveira de; FERREIRA, Nilce Vieira Campos. Formação de professoras normalistas rurais nos longínquos rincões do Território Federal do Guaporé, ao norte do brasil, em Porto Velho/RO (1947 -1951). Revista Ibero-Americana de Estudos em Educação, Araraquara, v. 15, n. 2, p. 492-507, abr./jun. 2020. e-ISSN: 1982-5587. DOI: https://doi.org/10.21723/riaee.v15i2.12596

Submetido em: 29/05/2019

Revisões requeridas: $18 / 08 / 2019$

Aprovado em: 20/10/2019

Publicado em: 20/02/2020 